\title{
Frailty and Sarcopenia Assessment upon Hospital Admission to Internal Medicine Predict Worse Short-term Clinical Outcomes. 1- Year, Prospective Study of 980 patients.
}

Sapir Anani

Sheba Medical Center at Tel Hashomer

Gal Goldhaber

Sheba Medical Center at Tel Hashomer

Adi Brom

Sheba Medical Center at Tel Hashomer

Nir Lasman

Sheba Medical Center at Tel Hashomer

Natia Turpashvili

Sheba Medical Center at Tel Hashomer

Gilat Shenhav-Saltzman

Sheba Medical Center at Tel Hashomer

Chen Avaky

Sheba Medical Center at Tel Hashomer

Liat Negru

Sheba Medical Center at Tel Hashomer

Mochamad Agbaria

Sheba Medical Center at Tel Hashomer

Sigalit Ariam

Sheba Medical Center at Tel Hashomer

Doron Portal

Sheba Medical Center at Tel Hashomer

Yishay Wasserstrum

Sheba Medical Center at Tel Hashomer

Gad Gad ( $\square$ gad.segal@sheba.health.gov.il)

Sheba Medical Center at Tel Hashomer https://orcid.org/0000-0002-3851-3245

Research article

Keywords: Sarcopenia, Frailty, ALT, MAMC, FRAIL Questionnaire, Internal medicine

Posted Date: June 25th, 2020

DOI: https://doi.org/10.21203/rs.3.rs-36718/v1

License: @ (1) This work is licensed under a Creative Commons Attribution 4.0 International License. Read Full License 


\begin{abstract}
Background. Frailty and sarcopenia are associated with frequent hospitalizations and poor clinical outcomes in geriatric patients. Ascertaining this association for younger patients hospitalized to internal medicine departments could help better prognostication of patients in the realm of internal medicine.

Methods. During 1-year prospective study in an internal medicine department, we evaluated patients upon admission for sarcopenia and frailty. We used the FRAIL questionnaire, blood Alanine-amino transferase (ALT) activity and Mid-Arm Muscle Circumference (MAMC) measurements.
\end{abstract}

Results. We recruited Nine-hundred and eighty consecutive patients upon hospital admission (median age 72 years (IQR 65-79); 56.8\% males). According to the FRAIL questionnaire 106 (10.8\%) patients were robust, 368 (37.5\%) pre-frail and 506 (51.7\%) were frail. The Median ALT value was 19IU/L (IQR 14-28). The median MAMC value was 27.8 (IQR 25.7-30.2). Patients with low ALT activity level (< 17IU/L) were more frail according to their FRAIL score (3 (IQR 2-4) vs. 2 (IQR 1-3); p < 0.001). Higher MAMC values were associated with higher ALT activity, both representing robustness. The rate of 30 -days readmission in the whole cohort was $17.4 \%$. Frail patients according to the FRAIL score $(F S)$ had a higher risk for 30-days readmission (for $F S>2, H R=1.99 ; 95 \mathrm{Cl}=1.29-3.08 ; p=0.002$ ). Frail patients according to low ALT activity also had a significantly higher risk for 30 -days readmission $(H R=2.22 ; 95 \mathrm{Cl}=1.26-3.91 ; p=0.006)$. After excluding patients whose length of stay (LOS) was $\geq 10$ days, $252(27.5 \%)$ stayed in-hospital for 4 days or longer. Frail patients according to FS had a higher risk for LOS $\geq 4$ days (for $F S>2, H R=1.87 ; 95 \mathrm{Cl}=1.39-2.52 ; \mathrm{p}<0.001$ ). Frail patients according to low ALT activity were also at higher risk for LOS $\geq 4$ days $(\mathrm{HR}=1.87 ; 95 \mathrm{Cl}=1.39-2.52 ; \mathrm{p}<0.001)$. MAMC values were not correlated with patients' LOS or risk for re-admission.

Conclusion. Frailty and sarcopenia upon admission to internal medicine departments are associated with longer hospitalization and increased risk for re-admission.

\title{
Background
}

\section{The need for internal medicine personalization, hospital length-of-stay and re- admissions}

The burden, both in public-health outcomes and healthcare associated expenditures, on the hospitalization resources of internal medicine departments, worldwide, is ever growing. This is the result, in developed countries, of population growth, especially in the adult and old age $(1,2)$. Improvement of prognostication measures, e.g. better appreciation of hospitalization length of stay and rate of re-hospitalizations would be therefore, of utmost importance. Improvement of such prognostication would improve the adjustment of procedures done during the hospital stay, both diagnostic and therapeutic, for patients' nature. In other words, such measures will serve as true personalization of the internal medicine services delivered in hospitals worldwide.

Personalization of patients' care in internal medicine departments refer to both estimation of length-of-stay and the anticipated rate of readmissions. If both end-points' appreciation would be better predicted, significant changes in hospital patients' care could be made. Regarding length of hospital stay, it is known that a better triage of patients, upon admission, could decrease the rate of patients transfer to intermediate care units that is associated with increased LOS $(3,4)$. Hospital readmissions are a worldwide, major health-care burden, with negative impact on patients' health, public health and healthcare systems' associated national financial burden. Previous publications describe the heavy toll of hospital (non-surgical) re-admissions while the same researchers and others attempted various strategies for either predicting the risk for readmission and proactively reducing it (albeit with conflicting results) (5-10).

\section{Sarcopenia and frailty assessment and their prognostic implications in the realm of internal medicine}

Sarcopenia and frailty are long recognized as syndromes associated with old age, with negative impact on the risk of falls, failure of inhospital rehabilitation, higher rates of hospital admissions and increased risk of death (11-13). In the past few years, several researchers have demonstrated the importance of sarcopenia and frailty assessment in a younger patients' population, either hospitalized in the departments of internal medicine (14) or in an ambulatory setting (15-18). Several methods for sarcopenia and frailty assessments are available, some of which are less applicable in the setting of acute, internal medicine, hospitalizations (e.g. DEXA (Dual-energy X-ray absorptiometry test) or TUG (timed up and go test)). Nevertheless, some assessments are readily available for such patients, including alanine-aminotransferase (ALT) activity level measurements (19) and short questionnaires, like FRAIL (14). 
In a previous, retrospective study, we have already established an association between low ALT values and high FRAIL questionnaire score, both with each other and with increased risk of mortality in the population of internal medicine patients (14). In the current study, we aimed at prospectively assessing the value of a multi-modal sarcopenia and frailty assessment upon hospital admission, the correlation between different indices of sarcopenia and frailty and the extent to which such indices would be associated with poor short-term clinical outcomes.

\section{Methods}

\section{Patients and methods}

After approval by an institutional review board, we recruited consecutive patients according to the following inclusion criteria: a). Age within the range of 55 to 85 years. We intentionally exclude the oldest patients for whom, frailty assessment is redundant, b). Admitted to the internal medicine department via the emergency department as acute in-patients. We excluded the following patients: a). Advanced (stage IV malignancy), b). Chronic obstructive pulmonary disease (COPD) patients classified as GOLD stage IV, c). Progressive dementia, d). Patients admitted due to diabetic foot and / or severe peripheral vascular disease, e). Congestive heart failure (CHF) patients classified as NYHA stages III or IV, f). A history of major stroke, g). Classified as advanced / end-stage cirrhosis, h). Patients classified as bedridden for any cause, i). Necessitating mechanical ventilation upon admission, Patients hospitalized during the past 30 days. None of the aforementioned patients would benefit from diagnosis as frail since their basic characteristics, to begin with, foresee a grim prognosis. Patients with ALT values greater than $40 \mathrm{IU} / \mathrm{L}$ were excluded from analysis (regarding ALT, as detailed later).

Upon admission, all eligible patients went through the following assessments:

\section{FRAIL questionnaire}

Either as part of more comprehensive indices or as stand-alone measurements, there are several validated questionnaires serving as assessment tools for frailty. One such questionnaire we were familiar with was the FRAIL questionnaire. The FRAIL questionnaire includes five components: Fatigue, Resistance, Ambulance, Illnesses and Loss of weight. FRAIL scores represent frail (3-5), pre-frail (1-2) and robust (0) health statuses. The FRAIL questionnaire was validated in a group of African Americans, age 49 to 65 years (20). Morley, Malmstrom, and Miller did a cross-validation and found out that the FRAIL scale correlated significantly with IADL (instrumental activities of daily life) difficulties, handgrip strength, and one-leg stand among participants who had no baseline ADL difficulties. This correlation was demonstrated for subjects with no baseline ADL problems. The results of this longitudinal study showed that the "pre-frail" definition by FRAIL at baseline was associated with statistical significance, future ADL difficulties, worse one-leg standing, and mortality. Scoring as "frail" in the FRAIL at baseline was associated with future ADL difficulties, IADL difficulties, and increased risk of mortality. The FRAIL questionnaire is a practical and useful assessment tool that has been recommended by others (21). A single researcher interviewed and filled the FRAIL questionnaire for all eligible patients in the current study.

\section{Mid-Arm Muscle Circumference (MAMC) measurement}

All anthropometric measurements are generally considered less accurate than other measurement methods, and their results are highly operator-dependent. As such, anthropometric measurements necessitate usage of reliable, professional instruments, experienced testers, and application of repeated and/or multiple measurements.

There are several anthropometric measurements that are based on assessing LBM (lean body mass) and total body muscular mass via assimilating limb circumference and skin-fold measurements into equations giving net muscle dimension and volume. Skin-fold measurements, applied by a caliper, are widely used for assessing percentage of fat tissue within the body. Caliper measurements of the biceps skin fold, triceps skin fold or iliac skin fold can be placed into tables, showing normal distribution of skin-fold thickness according to gender and age. The MAMC (mid-arm muscle circumference) equation uses the upper-limb, the mid-way arm circumference measurement of the arm (MAC), and the TSF (triceps skin fold) measurement. The MAC and TSF measurement results are assimilated into the following equation: MAMC = MAC - (3.14 x TSF) (22). The MAMC value was plotted in gender-specific tables. These tables were compiled from an historic cross-sectional sample of 19,097 white subjects, incorporated into the United States Health and Nutritional Examination Survey of 1971 to 1974 (23). We chose the MAMC as our anthropometric "representative" since it gained relative confidence among researchers compared with other anthropometric methods for sarcopenia assessment (24-29).

In a similar manner to what we did regarding the FRAIL questionnaire, a single researcher did all MAMC measurements for all eligible patients in the current study. In our analyses, we included both raw values of MAMC measurements and percentiles drawn from the US population surveys. Since the MAMC had never been validate to the Israeli population, we preferred not to rely only on population percentile normalizations. 


\section{ALT measurement}

Alanine amino transferase (ALT; also known as SGPT, serum glutamic pyruvic transaminase) is the enzyme responsible for reversible transamination between alanine and 2-oxoglutarate to generate pyruvate and glutamate. As such, this fundamental enzyme plays a key role in the intermediary metabolism of glucose and amino acids $(30,31)$. Since ALT activity in the liver is about 3,000 times as high as in the serum, its main purpose in clinical testing is to rule out hepatocellular injury. The amount of ALT in tissues other than the liver, like the skeletal muscle tissue, is much lower. ALT activity levels are significantly decreased among end stage renal disease (ESRD) patients treated by hemodialysis, also, ALT activity levels are measured as lower in patients who are taking medications that involve/recruit the catalytic activity of P-5-P, thereby lowering ALT activity, dependent of this co-enzyme (such as dopaminergic medications used for Parkinson's disease). The upper limit of normal (ULN) for ALT peripheral blood activity is approximately $40 \mathrm{IU}$. Above this level of activity in the blood, we assume that ALT is pouring out of cellular tissues. Consequently, patients with such ALT measurements were excluded from analysis whenever incorporating ALT patients' values. There are several comprehensive publications describing the association between decreased level of ALT activity in the peripheral blood, sarcopenia, frailty, and increased risk of all-cause mortality in middle-aged, heterogeneous populations (32-39).

\section{Statistical analysis}

All variables were described according to their properties. Categorical variables are reported in frequencies and percentages, and the difference between groups was tested with the Chi-square test. Continuous variables will be explored using a histogram plot and the Shapiro-Wilk test. Variables found to have a normal distribution are reported as mean and standard deviation values, and the differences between groups were tested with the T-test method. Continuous variables that did not have a normal distribution are reported as median and interquartile range (IQR, 25th-75th percentiles), and the difference between groups was tested with the Mann-Whitney $\mathrm{U}$ test.

We preformed regressions models for 2 outcomes: a Cox-regression for 30-day hospital readmission, and a logistic regression model for prolonged length of stay, defined as hospitalizations lasting 3-10 days (longer hospitalizations were excluded, since these were mostly due to non-medical issues). The model was adjusted for age, gender, diabetes mellitus, chronic kidney disease, an active malignancy, the FRAIL score and serum ALT.

The statistical analysis was carried out with the use of R version 3.6.1 software (The R Foundation) and R-studio 1.2.5001 (R Studio, Inc.).

\section{Results}

Over 12 months duration we recruited 980 consecutive patients that were eligible according to the inclusion criteria and signed an informed consent. Table 1 present patients' characteristics, according to their status of 30-day re-admission. The median age was 72 years (IQR 6579) with $56.8 \%$ male patients. The following characteristics were found to be significantly different between patients who were re-admitted during 30 days after discharge and those who did not: Amongst re-admitted patients there was a longer length of hospital stay: median LOS 3 [IQR; 2.00, 5.00] vs. 2 days [IQR; 1.00, 4.00], p = 0.015. In addition, re-admitted patients were more likely to come from nursing homes: $7.6 \%$ vs. $2 \%, p=0.004$ (for the overall difference in outpatients' settings). Cirrhosis was also more prevalent amongst re-admitted patients (3.3\% vs. $0.5 \%, p=0.017)$. Laboratory parameters that were significantly different included lower hemoglobin concentration $(11.8 \mathrm{~g} / \mathrm{dL}$ vs. $12.8 \mathrm{~g} / \mathrm{dL}, \mathrm{p}<0.001)$ and higher creatinine concentration $(1.08 \mathrm{mg} / \mathrm{dL}$ vs. $0.96 \mathrm{mg} / \mathrm{dL}, \mathrm{p}=0.048)$ amongst patients with a 30 -days readmission. Patients' characteristics associated with sarcopenia and frailty that were found to be significantly different in patients with or without a 30-days re-admission event were a lower level of ALT blood activity (median $11 \mathrm{IU}$ vs. $14 \mathrm{IU}, p=0.005$ ) and a higher frail score (median 3 vs. 2.5, $p$ < 0.001). MAMC values were not significantly different between these two groups of patients. 
Table 1

Patients' characteristics according to 30-day readmission status.

\begin{tabular}{|c|c|c|c|}
\hline & \multicolumn{3}{|c|}{ 30-day readmission status } \\
\hline & No $(N=888)$ & Yes $(\mathbb{N}=92)$ & $\mathbf{p}$ \\
\hline LOS; days (median [IQR]) & $2.00[1.00,4.00]$ & $3.00[2.00,5.00]$ & 0.015 \\
\hline \multicolumn{4}{|l|}{ Patient demographics } \\
\hline Female gender; $\mathrm{N}(\%)$ & $380(42.8)$ & $43(46.7)$ & 0.537 \\
\hline Age (Years); (median [IQR]) & $72.00[65.00,79.00]$ & $74.00[65.75,79.50]$ & 0.344 \\
\hline BMI (median [IQR]) & $27.12[24.30,31.22]$ & $26.93[23.51,30.79]$ & 0.591 \\
\hline Norton score (median [IQR]) & $19.00[17.00,20.00]$ & $18.00[17.00,19.00]$ & 0.167 \\
\hline Married; N (\%) & $573(64.5)$ & $49(53.3)$ & 0.14 \\
\hline \multicolumn{3}{|l|}{ Outpatient setting, before admission; N (\%) } & \multirow[t]{4}{*}{0.005} \\
\hline Community & $833(93.8)$ & $84(91.3)$ & \\
\hline Nursing home & $18(2.0)$ & $7(7.6)$ & \\
\hline Long-term facility & $15(1.7)$ & $1(1.1)$ & \\
\hline \multicolumn{4}{|l|}{ Background diagnoses; N (\%) } \\
\hline IHD; Ischemic heart disease & $303(34.1)$ & $41(44.6)$ & 0.060 \\
\hline CHF; Congestive heart failure & $75(8.4)$ & $12(13.0)$ & 0.199 \\
\hline Atrial fibrillation & $174(19.6)$ & $25(27.2)$ & 0.113 \\
\hline DM; Diabetes mellitus & $406(45.7)$ & $52(56.5)$ & 0.062 \\
\hline Hypoglycemia during hospitalization & $5(0.8)$ & $1(1.6)$ & 0.007 \\
\hline Status post stroke & $138(15.5)$ & $18(19.6)$ & 0.393 \\
\hline Dementia & $13(1.5)$ & $0(0.0)$ & 0.490 \\
\hline CRF; Chronic renal failure & $138(15.5)$ & $14(15.2)$ & 1.000 \\
\hline Chronic obstructive pulmonary disease & $174(19.6)$ & $20(21.7)$ & 0.723 \\
\hline Liver cirrhosis & $4(0.5)$ & $3(3.3)$ & 0.017 \\
\hline Solid malignancy & $106(11.9)$ & $10(10.9)$ & 0.895 \\
\hline \multicolumn{4}{|l|}{ Laboratory parameters (median [IQR]) } \\
\hline $\mathrm{HB} ; \mathrm{g} / \mathrm{dL}$ & $12.79[11.39,14.12]$ & $11.77[10.46,12.96]$ & $<0.001$ \\
\hline CREAT; mg/dL & $0.96[0.75,1.29]$ & $1.08[0.77,1.66]$ & 0.048 \\
\hline Albumin; g/dL & $3.80[3.50,4.10]$ & $3.80[3.50,4.00]$ & 0.198 \\
\hline \multicolumn{4}{|l|}{ Frailty Parameters } \\
\hline ALT; (IU; median [IQR]) & $14.00[10.00,18.00]$ & $11.00[9.00,15.50]$ & 0.005 \\
\hline FRAIL questionnaire score (median [IQR]) & $2.50[1.00,3.00]$ & $3.00[2.00,4.00]$ & $<0.001$ \\
\hline MAMC percentile (median [IQR]) & $87.50[58.80,98.00]$ & $86.05[53.57,98.00]$ & 0.536 \\
\hline
\end{tabular}


Table 2

Cohort according to LOS (patients whose LOS $\geq 14$ days excluded).

\begin{tabular}{|c|c|c|c|}
\hline & \multicolumn{2}{|c|}{ Length of hospital stay $\geq 3$ days } & \multirow[t]{2}{*}{$\mathbf{p}$} \\
\hline & No $(N=504)$ & Yes $(N=456)$ & \\
\hline 30-day readmission & $38(7.5)$ & $56(12.3)$ & 0.018 \\
\hline \multicolumn{4}{|l|}{ Patient demographics } \\
\hline Female gender; $\mathrm{N}(\%)$ & $216(42.9)$ & $199(43.6)$ & 0.858 \\
\hline Age (Years); (median [IQR]) & $71.00[64.00,78.00]$ & $73.00[65.00,80.00]$ & 0.005 \\
\hline BMI (median [IQR]) & $27.16[24.55,31.20]$ & $27.06[23.95,31.22]$ & 0.648 \\
\hline Norton score (median [IQR]) & $19.00[18.00,20.00]$ & $18.00[15.00,19.00]$ & $<0.001$ \\
\hline Married; N (\%) & $337(66.9)$ & $275(60.3)$ & 0.041 \\
\hline \multicolumn{3}{|l|}{ Outpatient setting, before admission; N (\%) } & \multirow[t]{4}{*}{0.027} \\
\hline Community & $486(96.4)$ & 419 (91.9) & \\
\hline Nursing home & $8(1.6)$ & $16(3.5)$ & \\
\hline Long-term facility & $4(0.8)$ & $8(1.8)$ & \\
\hline \multicolumn{4}{|l|}{ Background diagnoses; N (\%) } \\
\hline IHD; Ischemic heart disease & $167(33.1)$ & $173(37.9)$ & 0.137 \\
\hline CHF; Congestive heart failure & $42(8.3)$ & $44(9.6)$ & 0.549 \\
\hline Atrial fibrillation & $96(19.0)$ & $101(22.1)$ & 0.268 \\
\hline DM; Diabetes mellitus & $223(44.2)$ & $223(48.9)$ & 0.168 \\
\hline Hypoglycemia during hospitalization & $2(0.5)$ & $4(1.3)$ & 0.503 \\
\hline Status post stroke & $78(15.5)$ & $77(16.9)$ & 0.614 \\
\hline Dementia & $10(2.0)$ & $3(0.7)$ & 0.135 \\
\hline CRF; Chronic renal failure & $67(13.3)$ & $81(17.8)$ & 0.068 \\
\hline Chronic obstructive pulmonary disease & $92(18.3)$ & $98(21.5)$ & 0.240 \\
\hline Liver cirrhosis & $4(0.8)$ & $3(0.7)$ & 1.000 \\
\hline Solid malignancy & $56(11.1)$ & $57(12.5)$ & 0.571 \\
\hline \multicolumn{4}{|l|}{ Laboratory parameters (median [IQR]) } \\
\hline $\mathrm{HB} ; \mathrm{g} / \mathrm{dL}$ & $13.08[11.85,14.33]$ & $12.23[10.74,13.63]$ & $<0.001$ \\
\hline CREAT; mg/dL & $0.92[0.73,1.15]$ & $1.04[0.79,1.54]$ & $<0.001$ \\
\hline Albumin; g/dL & $3.90[3.70,4.20]$ & $3.70[3.30,4.00]$ & $<0.001$ \\
\hline \multicolumn{4}{|l|}{ Frailty Parameters } \\
\hline ALT; (median [IQR]) & $14.00[10.00,19.00]$ & $12.00[9.00,17.00]$ & $<0.001$ \\
\hline FRAIL questionnaire (FQ) total score & $2.00[1.00,3.00]$ & $3.00[2.00,4.00]$ & $<0.001$ \\
\hline MAMC percentile (median [IQR]) & $28.22[25.84,30.25]$ & $27.70[25.48,29.90]$ & 0.148 \\
\hline MAMC, Mid-are muscle circumference & & & \\
\hline
\end{tabular}

Table two present patients' characteristics according to the length of hospital stay. After we excluded patients hospitalized for more than 14 days (many of whom had socio-economic rather than medical barriers for discharge), amongst patients who had a longer LOS (over 3 days duration), several characteristics were significantly different: These patients were older (median age 73 vs. 71, p = 0.008), their 30-day readmission rates were higher $(12.2 \%$ vs. $7.5 \%, p=0.019)$, they had lower Norton and Morse scores $(18$ vs. $19, p<0.001$ and 7 vs. $6, p=0.001$, 
respectively) and a lower proportion were married (59.9\% vs. $66.9 \%, p=0.027)$. Laboratory parameters were also significantly different between these patients groups: patients with longer hospital stay had lower hemoglobin concentration $(12.2 \mathrm{~g} / \mathrm{dL} \mathrm{vs}$. $13.1 \mathrm{~g} / \mathrm{dL}, \mathrm{p}<0.001)$, higher creatinine concentrations $(1.05 \mathrm{mg} / \mathrm{dL}$ vs. $0.92 \mathrm{mg} / \mathrm{dL}, \mathrm{p}<0.001)$, higher urea concentration $(48 \mathrm{mg} / \mathrm{dL}$ vs. $41 \mathrm{mg} / \mathrm{dL}, \mathrm{p}<0.001)$, lower albumin concentration $(3.7 \mathrm{~g} / \mathrm{dL}$ vs. $3.9 \mathrm{~g} / \mathrm{dL}, \mathrm{p}<0.001)$ and higher CRP concentration $(26.3 \mathrm{mg} / \mathrm{L}$ vs. $7.2 \mathrm{mg} / \mathrm{L}, \mathrm{p}<0.001)$. Patients' characteristics associated with sarcopenia and frailty that were found to be significantly different in patients with longer hospitalizations were lower level of ALT (median 12 IU vs. 14 IU, $p<0.001$ ) and higher FRAIL score (median 3 vs. 2, $p<0.001$ ). MAMC values were not significantly different between these two groups of patients.

Two of the measures for sarcopenia and frailty used in this study: ALT activity measurement in the peripheral blood the FRAIL questionnaire, were not only found to be associated with higher risks for longer hospitalization and 30-days re-admission but were also found to be in correlation with each other. As presented in Table 3 and Fig. 3, both ALT and Frailty Score (FS) had statistically significant correlation with each other and with the MAMC measurements, although, the later was not associated with clinical outcomes. Figure 1 show a survival curve for 30-days readmission events according to FRAIL questionnaire classes $(p=0.0019)$ and Fig. 2 show a survival curve for 30 -days readmission events according to ALT activity lower than $12 \mathrm{IU}(\mathrm{p}<0.0001)$.

Table 3

Associations between different sarcopenia and frailty indices.

\begin{tabular}{|c|c|c|c|c|c|}
\hline & $\mathbf{N}$ & ALT $<12$ IU & $\mathbf{N}$ & $A L T \geq 12$ IU & $\mathbf{p}$ \\
\hline $\begin{array}{l}\text { Frail score } \\
\text { (median (IQR)) }\end{array}$ & 411 & $3(2.0-4.0)$ & 227 & $2(1.0-3.0)$ & $<0.001$ \\
\hline \multirow{2}{*}{$\begin{array}{l}\text { MAMC } \\
\text { (median (IQR)) }\end{array}$} & 411 & $26.81[24.84,29.47]$ & 227 & $28.31[26.12,30.59]$ & $<0.001$ \\
\hline & $\mathbf{N}$ & Frail score 3-5 & $\mathbf{N}$ & Frail score 0-2 & $\mathbf{p}$ \\
\hline $\begin{array}{l}\text { ALT } \\
\text { (median (IQR)) }\end{array}$ & 322 & $15.00[11.00,19.00]$ & 316 & $11.50[9.00,17.00]$ & $<0.001$ \\
\hline $\begin{array}{l}\text { MAMC } \\
\text { (median (IQR)) }\end{array}$ & 506 & $28.15[25.84,30.62]$ & 474 & $27.72[25.41,29.81]$ & 0.04 \\
\hline
\end{tabular}

In the adjusted model for 30-day readmission, ALT activity levels under 12 IU and a FRAIL score of 3 or greater were predictive for 30-day readmission (HR 2.06 [95\% $\mathrm{Cl} 1.34-3.16]$ and $\mathrm{HR} 1.59$ [95\% $\mathrm{Cl} 1.02-2.48]$, respectively).

In a multivariate model for prolonged hospital stay (3-14 days), lower ALT levels and a higher FRAIL score were the only significant predictive factors (HR 1.33 [95\% Cl 1.00-1.76] and HR 1.55 [95\% Cl 1.18-2.04], respectively).

In a subgroup analysis described in Fig. 4, a lower ALT was significantly associated with 30-day readmission across most subgroups, except for a higher serum albumin level defined as > $3.5 \mathrm{~g} / \mathrm{dl}(\mathrm{n}=250, \mathrm{HR} 1.8$ [95\% Cl 0.84-3.90]), with no significant interactions between ALT levels and the various stratifying variables.

\section{Discussion}

Immense efforts, in time, work force and resources, are invested in making hospitalization in internal medicine department better - for the sake of patients, stability and quality of staff and in order to diminish the ever-growing healthcare associated expenses. Many of these efforts delineate the need to reduce re-admissions and shorten hospital length-of-stay. We suggest that personalization of internal medicine is the key for achieving the aforementioned targets. In contrast to precise medicine, in which the disease is better characterized and targeted (as is the case with modern oncology), we believe that personal medicine, in the realm of internal medicine, should target sarcopenia and frailty. As stated earlier, these syndromes are well described and attended in the fields of geriatrics and gerontology. Preceding old age, by identifying middle-aged patients as frail, could better their prognostication and make their in-hospital management, more accurate and more personalized.

Of the many available methods for sarcopenia and frailty assessment, we chose, for the current study, three, potentially complimentary approaches: one, a phenotypic assessment reflecting the consequences of frailty in daily life - the FRAIL questionnaire. The second approach, addressing the sarcopenic phenotype in a more mechanistic way: the measurement of skeletal mass in conjugation with the 
amount of sub-cutaneous fat - the MAMC measurement (including the MAC and the TSF measurements). Last, but not least, the ALT activity measurement, also addressing the net skeletal mass in the body, avoiding the boas of anthropometric measurements and readily available for all hospitalized patients as well as the majority of community dwelling population. The relative advantages and disadvantages of each methods are described earlier.

Our study had several limitations: this was a single-center study. Therefore, it is possible that a selection-bias has influenced our results. In addition, long-term clinical outcomes were not reported at the time of data analysis.

\section{Conclusions}

In light of our results, the following conclusions are derived: A). ALT measurements and FRAIL questioner results can serve as easy to get assessment tools, predicting the risk for re-admission and longer length of hospital stay. Both tools were found to have significantly statistical correlation with these clinical outcomes and with each other. B). MAMC measurement is not recommended as a tool for sarcopenia and frailty assessment in the setting of internal medicine department.

It is advised that in the coming future, two main research aims should be sought: A). longer follow-up should clear the question whether indeed, sarcopenia and frailty, according to FRAIL and ALT assessments are also indicative of worse, long-term clinical outcomes (such as 5years survival). B). Which in-hospital interventions have the potential to achieve better clinical outcomes in face of sarcopenia and frailty. For example, would diabetic patients enjoy better outcomes when their glycemic control is more tight or loose in face of their being frail? Would longer intravenous antibiotics be given to frail, middle aged patients prior to discharge? Should robust patients be directed to hospital-at-home settings after initial triage and frailty assessment in the emergency department? These questions and more should be the aim of future clinical investigations.

\section{Abbreviations}

\section{ALT}

Alanine-amino transferase

MAMC

Mid-arm muscle circumference

IQR

Inter-quartile range

FS

Frailty score

HR

Hazard ratio

$\mathrm{Cl}$

Confidence interval

LOS

Length of (hospital) stay

DEXA

Dual-energy X-ray absorptiometry (test)

COPD

Chronic obstructive pulmonary disease

NYHA

New York heart association (staging)

IU

International unit

ADL/IADL

Activities of daily life / Instrumental ADL

MAC

Mid-arm circumference

TSF

Triceps skin fold

ESRD

End-stage renal disease 
ULN

Upper limit (of) normal

CRP

C-Reactive protein

BMI

Body mass index

\section{Declarations}

Ethics approval and consent to participate

An institutional review board at the Chaim Sheba medical center approved this study prior to initiation.

Consent for publication

All authors gave their consent to this publication

Data availability.

All the clinical data on which we relied is available in an anonymized manner for further analysis upon request

Competing interests

All authors declare they have no competing interests relevant to this study and manuscript

Funding

There was no external funding resource to this study aside from a donation, by the Shalvi family foundation, dedicated to clinical research

Authors' contributions

All authors did a significant contribution to this study and writing the manuscript

Acknowledgements

N/A

\section{References}

1. Luben R, Hayat S, Wareham N, Pharoah P, Khaw K-T. Usual physical activity and subsequent hospital usage over 20 years in a general population: the EPIC-Norfolk cohort. BMC Geriatr [Internet]. 2020 [cited 2020 May 22];20. Available from: https://www.ncbi.nlm.nih.gov/pmc/articles/PMC7204050/.

2. JL D, C JCAC. C, Z L, A L, et al. US Health Care Spending by Payer and Health Condition, 1996-2016. JAMA [Internet]. 2020 [cited 2020 May 22];323(9). Available from: https://pubmed.ncbi.nlm.nih.gov/32125402/? from_term=\%28\%28hospital\%29+AND+\%28elderly\%29\%29+AND+\%28expenditures\%29\&from_sort=date\&from_size=200\&from_pos=31.

3. SJ DS, MR T, NR B. H, HL G. Increased Inpatient Length of Stay After Early Unplanned Transfer to Higher Levels of Care. Crit care Explor [Internet]. 2020 [cited 2020 May 22];2(4). Available from: https://pubmed.ncbi.nlm.nih.gov/32426745/?

from_term=\%28internal+medicine\%29+AND+\%28length+of+stay\%29\&from_sort=date\&from_size=200\&from_pos=4.

4. LC B, J de G JAL, SCE SAJA. S, et al. The APOP Screener and Clinical Outcomes in Older Hospitalised Internal Medicine Patients. Neth J Med [Internet]. 2020 [cited 2020 May 22];78(1). Available from: https://pubmed.ncbi.nlm.nih.gov/32043475/?

from_term=\%28internal+medicine\%29+AND+\%28length+of+stay\%29\&from_sort=date\&from_size=200\&from_pos=173.

5. Nall RW, Herndon B, Mramba LK, Vogel-Anderson K, Hagen MG. An Interprofessional Primary Care Based Transition of Care Clinic to Reduce Hospital Readmission. Am J Med [Internet]. 2019 Dec 23 [cited 2020 Jan 6]; Available from:

http://www.ncbi.nlm.nih.gov/pubmed/31877267.

6. Sunkara PR, Islam T, Bose A, Rosenthal GE, Chevli P, Jogu H, et al. Impact of structured interdisciplinary bedside rounding on patient outcomes at a large academic health centre. BMJ Qual Saf [Internet]. 2019 Dec 6 [cited 2020 Jan 6];bmjqs-2019-009936. Available from: http://www.ncbi.nlm.nih.gov/pubmed/31810994. 
7. Ibrahim AM, Koester C, Al-Akchar M, Tandan N, Regmi M, Bhattarai M, et al. HOSPITAL Score, LACE Index and LACE + Index as predictors of 30-day readmission in patients with heart failure. BMJ Evidence-Based Med [Internet]. 2019 Nov 26 [cited 2020 Jan 6];bmjebm-2019-111271. Available from: http://www.ncbi.nlm.nih.gov/pubmed/31771947.

8. Gentene AJ, Guido MR, Woolf B, Dalhover A, Boesken TA, Mueller EW, et al. Multidisciplinary Team Utilizing Pharmacists in Multimodal, Bundled Care Reduce Chronic Obstructive Pulmonary Disease Hospital Readmission Rates. J Pharm Pract [Internet]. 2019 Nov 26 [cited 2020 Jan 6];089719001988944. Available from: http://www.ncbi.nlm.nih.gov/pubmed/31769330.

9. $10.1186 /$ s12913-019-4528-9

Lembeck MA, Thygesen LC, Sørensen BD, Rasmussen LL, Holm EA. Effect of single follow-up home visit on readmission in a group of frail elderly patients - a Danish randomized clinical trial. BMC Health Serv Res [Internet]. 2019 Dec 25 [cited 2020 Jan 6];19(1):751. Available from: https://bmchealthservres.biomedcentral.com/articles/10.1186/s12913-019-4528-9.

10. Karapinar-Çarkıt F, Borgsteede SD, Janssen MJA, Mak M, Yildirim N, Siegert CEH, et al. The effect of a pharmaceutical transitional care program on rehospitalisations in internal medicine patients: an interrupted-time-series study. BMC Health Serv Res [Internet]. 2019 Dec 21 [cited 2020 Jan 6];19(1):717. Available from: http://www.ncbi.nlm.nih.gov/pubmed/31638992.

11. Marty E, Liu Y, Samuel A, Or O, Lane J. A review of sarcopenia: Enhancing awareness of an increasingly prevalent disease. Bone [Internet]. 2017 Dec [cited 2018 Feb 10];105:276-86. Available from: http://www.ncbi.nlm.nih.gov/pubmed/28931495.

12. Buckinx F, Croisier J-L, Reginster J-Y, Lenaerts C, Brunois T, Rygaert X, et al. Prediction of the Incidence of Falls and Deaths Among Elderly Nursing Home Residents: The SENIOR Study. J Am Med Dir Assoc [Internet]. 2018 Jan [cited 2020 Jan 6];19(1):18-24. Available from: http://www.ncbi.nlm.nih.gov/pubmed/28757332.

13. Gringauz I, Weismann J, Justo D, Adunsky A, Segal G. Alanine aminotransferase blood levels and rehabilitation outcome in older adults following hip fracture surgery. Int J Rehabil Res [Internet]. 2018 Mar 24 [cited 2018 Feb 17];41(1):41-6. Available from: http://www.ncbi.nlm.nih.gov/pubmed/29068797.

14. Irina G, Refaela C, Adi B, Avia D, Liron H, Chen A, et al. Low Blood ALT Activity and High FRAlL Questionnaire Scores Correlate with Increased Mortality and with Each Other. A Prospective Study in the Internal Medicine Department. J Clin Med [Internet]. 2018 Oct 25 [cited 2020 Jan 6];7(11):386. Available from: http://www.ncbi.nlm.nih.gov/pubmed/30366377.

15. Portal D, Hofstetter L, Eshed I, Dan Lantsman C, Sella T, Urban D, et al. L3 skeletal muscle index (L3SMI) is a surrogate marker of sarcopenia and frailty in non-small cell lung cancer patients. Cancer Manag Res [Internet]. 2019 Apr [cited 2020 Jan 6];Volume 11:2579-88. Available from: http://www.ncbi.nlm.nih.gov/pubmed/31114324.

16. Kogan M, Klempfner R, Lotan D, Wasserstrum Y, Goldenberg I, Segal G. Low ALT blood levels are associated with lower baseline fitness amongst participants of a cardiac rehabilitation program. J Exerc Sci Fit [Internet]. 2018 Apr 1 [cited 2018 Feb 18];16(1):1-4. Available from: https://www.sciencedirect.com/science/article/pii/S1728869X17300564.

17. Peltz-Sinvani N, Klempfner R, Ramaty E, Sela BA, Goldenberg I, Segal G. Low ALT Levels Independently Associated with 22-Year AllCause Mortality Among Coronary Heart Disease Patients. J Gen Intern Med [Internet]. 2015 Aug 6 [cited 2015 Dec 15 ]; Available from: http://www.ncbi.nlm.nih.gov/pubmed/26245731.

18. Ramaty E, Maor E, Peltz-Sinvani N, Brom A, Grinfeld A, Kivity S, et al. Low ALT blood levels predict long-term all-cause mortality among adults. A historical prospective cohort study. Eur J Intern Med. 2014 Dec;25(10):919-21.

19. Ramati E, Israel A, Tal Kessler, Petz-Sinuani N, Sela B-A, Idan Goren, et al. [Low ALT activity amongst patients hospitalized in internal medicine wards is a widespread phenomenon associated with low vitamin B6 levels in their blood]. Harefuah [Internet]. 2015 Feb [cited 2015 Jun 5];154(2):89-93, 137. Available from: http://www.ncbi.nlm.nih.gov/pubmed/25856859.

20. Morley JE, Malmstrom TK, Miller DK. A simple frailty questionnaire (FRAIL) predicts outcomes in middle aged African Americans. J Nutr Health Aging [Internet]. 2012 Jul [cited 2017 Aug 13];16(7):601-8. Available from: http://www.ncbi.nlm.nih.gov/pubmed/22836700.

21. Singh M, Stewart R, White H. Importance of frailty in patients with cardiovascular disease. Eur Heart J [Internet]. 2014 Jul [cited 2018 Oct 4];35(26):1726. Available from: http://www.ncbi.nlm.nih.gov/pubmed/24864078.

22. Tosato M, Marzetti E, Cesari M, Savera G, Miller RR, Bernabei R, et al. Measurement of muscle mass in sarcopenia: from imaging to biochemical markers. Aging Clin Exp Res [Internet]. 2017 Feb 7 [cited 2018 Sep 24];29(1):19-27. Available from: http://www.ncbi.nlm.nih.gov/pubmed/28176249.

23. Frisancho AR. New norms of upper limb fat and muscle areas for assessment of nutritional status. Am J Clin Nutr [Internet]. 1981 Nov 1 [cited 2018 Sep 24];34(11):2540-5. Available from: http://www.ncbi.nlm.nih.gov/pubmed/6975564.

24. Cruz-Jentoft AJ, Baeyens JP, Bauer JM, Boirie Y, Cederholm T, Landi F, et al. Sarcopenia: European consensus on definition and diagnosis: Report of the European Working Group on Sarcopenia in Older People. Age Ageing [Internet]. 2010 Jul [cited 2017 Sep 23];39(4):412-23. Available from: http://www.ncbi.nlm.nih.gov/pubmed/20392703.

Page 10/14 
25. Wu L-W, Lin Y-Y, Kao T-W, Lin C-M, Liaw F-Y, Wang C-C, et al. Mid-arm muscle circumference as a significant predictor of all-cause mortality in male individuals. PLoS One [Internet]. 2017 [cited 2018 Sep 23];12(2):e0171707. Available from: http://www.ncbi.nlm.nih.gov/pubmed/28196081.

26. Noori N, Kopple JD, Kovesdy CP, Feroze U, Sim JJ, Murali SB, et al. Mid-Arm Muscle Circumference and Quality of Life and Survival in Maintenance Hemodialysis Patients. Clin J Am Soc Nephrol [Internet]. 2010 Dec 1 [cited 2018 Sep 23];5(12):2258-68. Available from: http://www.ncbi.nlm.nih.gov/pubmed/20947789.

27. Atkins JL, Whincup PH, Morris RW, Lennon LT, Papacosta O, Wannamethee SG. Sarcopenic Obesity and Risk of Cardiovascular Disease and Mortality: A Population-Based Cohort Study of Older Men. J Am Geriatr Soc [Internet]. 2014 Feb [cited 2018 Sep 23];62(2):253-60. Available from: http://www.ncbi.nlm.nih.gov/pubmed/24428349.

28. 10.1093/gerona/glq100

Wijnhoven $\mathrm{HAH}$, van Bokhorst-de van der Schueren MAE, Heymans MW, de Vet HCW, Kruizenga HM, Twisk JW, et al. Low Mid-Upper Arm Circumference, Calf Circumference, and Body Mass Index and Mortality in Older Persons. Journals Gerontol Ser A Biol Sci Med Sci [Internet]. 2010 Oct 1 [cited 2018 Sep 24];65A(10):1107-14. Available from: https://academic.oup.com/biomedgerontology/articlelookup/doi/10.1093/gerona/glq100.

29. Carnevale V, Castriotta V, Piscitelli PA, Nieddu L, Mattera M, Guglielmi G, et al. Assessment of Skeletal Muscle Mass in Older People: Comparison Between 2 Anthropometry-Based Methods and Dual-Energy X-ray Absorptiometry. J Am Med Dir Assoc [Internet]. 2018 Sep [cited 2018 Sep 23];19(9):793-6. Available from: http://www.ncbi.nlm.nih.gov/pubmed/29983360.

30. http://doi.wiley.com/10.1038/clpt.2012.108

Senior JR. Alanine Aminotransferase: A Clinical and Regulatory Tool for Detecting Liver Injury-Past, Present, and Future. Clin Pharmacol Ther [Internet]. 2012 Sep 8 [cited 2018 Feb 18];92(3):332-9. Available from: http://doi.wiley.com/10.1038/clpt.2012.108.

31. http://doi.wiley.com/10.1002/hep.22109

Kim WR, Flamm SL, Di Bisceglie AM, Bodenheimer HC. Serum activity of alanine aminotransferase (ALT) as an indicator of health and disease. Hepatology [Internet]. 2008 Jan 7 [cited 2018 Feb 18];47(4):1363-70. Available from: http://doi.wiley.com/10.1002/hep.22109.

32. Le Couteur DG, Blyth FM, Creasey HM, Handelsman DJ, Naganathan V, Sambrook PN, et al. The Association of Alanine Transaminase With Aging, Frailty, and Mortality. Journals Gerontol Ser A Biol Sci Med Sci [Internet]. 2010 Jul 1 [cited 2018 Feb 17];65A(7):712-7. Available from: http://www.ncbi.nlm.nih.gov/pubmed/20498223.

33. Gringauz I, Weismann J, Justo D, Adunsky A, Segal G. Alanine aminotransferase blood levels and rehabilitation outcome in older adults following hip fracture surgery. Int J Rehabil Res [Internet]. 2017 Oct 24 [cited 2018 Feb 4];1. Available from: http://www.ncbi.nlm.nih.gov/pubmed/29068797.

34. Vespasiani-Gentilucci U, De Vincentis A, Ferrucci L, Bandinelli S, Antonelli Incalzi R, Picardi A. Low Alanine Aminotransferase Levels in the Elderly Population: Frailty, Disability, Sarcopenia, and Reduced Survival. Journals Gerontol Ser A [Internet]. 2017 Jun 19 [cited 2018 Feb 17]; Available from: http://www.ncbi.nlm.nih.gov/pubmed/28633440.

35. Williams KH, Sullivan DR, Nicholson GC, George J, Jenkins AJ, Januszewski AS, et al. Opposite associations between alanine aminotransferase and $\mathrm{y}$-glutamyl transferase levels and all-cause mortality in type 2 diabetes: Analysis of the Fenofibrate Intervention and Event Lowering in Diabetes (FIELD) study. Metabolism [Internet]. 2016 May [cited 2018 Feb 17];65(5):783-93. Available from: http://www.ncbi.nlm.nih.gov/pubmed/27085785.

36. Peltz-Sinvani N, Klempfner R, Ramaty E, Sela BA, Goldenberg I, Segal G. Low. ALT Levels Independently Associated with 22-Year AllCause Mortality Among Coronary Heart Disease Patients. J Gen Intern Med [Internet]. 2016 Feb 6 [cited 2020 Jan 6];31(2):209-14. Available from: http://www.ncbi.nlm.nih.gov/pubmed/26245731.

37. Ramati E, Israel A, Tal Kessler, Petz-Sinuani N, Sela B-A, Idan Goren, et al. [Low ALT activity amongst patients hospitalized in internal medicine wards is a widespread phenomenon associated with low vitamin B6 levels in their blood]. Harefuah [Internet]. 2015 Feb [cited 2020 Jan 6];154(2):89-93, 137. Available from: http://www.ncbi.nlm.nih.gov/pubmed/25856859.

38. Ramaty E, Maor E, Peltz-Sinvani N, Brom A, Grinfeld A, Kivity S, et al. Low ALT blood levels predict long-term all-cause mortality among adults. A historical prospective cohort study. Eur J Intern Med [Internet]. 2014 Dec [cited 2015 Jun 5];25(10):919-21. Available from: http://www.ncbi.nlm.nih.gov/pubmed/25468741.

39. N NLMS. T, G G, Y L, E L, et al. Baseline Low ALT Activity Is Associated With Increased Long-Term Mortality After COPD Exacerbations. BMC Pulm Med [Internet]. 2020 [cited 2020 May 16];20(1). Available from: https://pubmed.ncbi.nlm.nih.gov/32393221/? from_term=\%28\%28ALT\%29+AND+\%28frailty\%29\%29+AND+\%28sarcopenia\%29\&from_filter=ds1.y_5\&from_size=200\&from_pos=6.

\section{Figures}




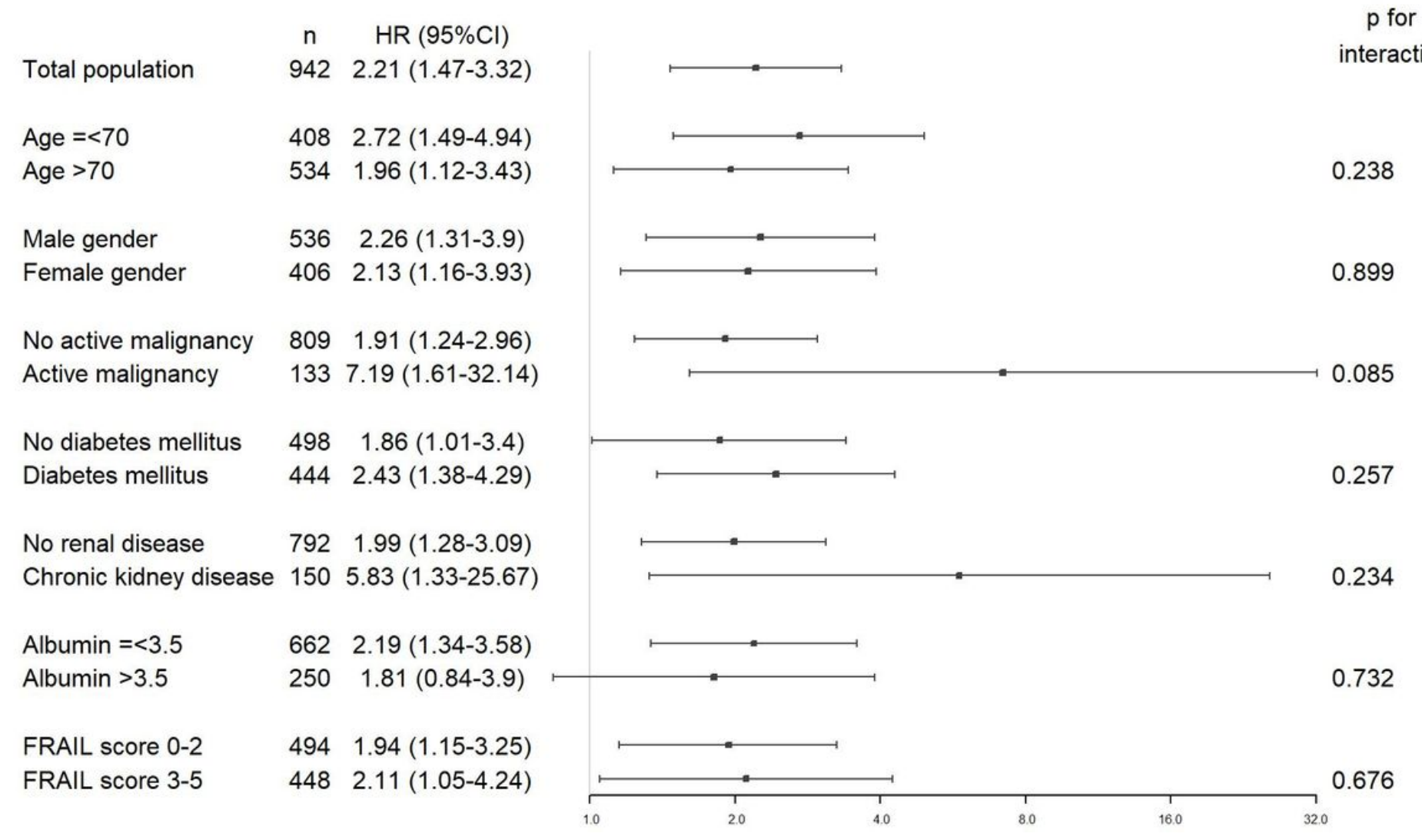

Figure 1

Sub-group analysis for lower ALT values and selected patients' characteristics.
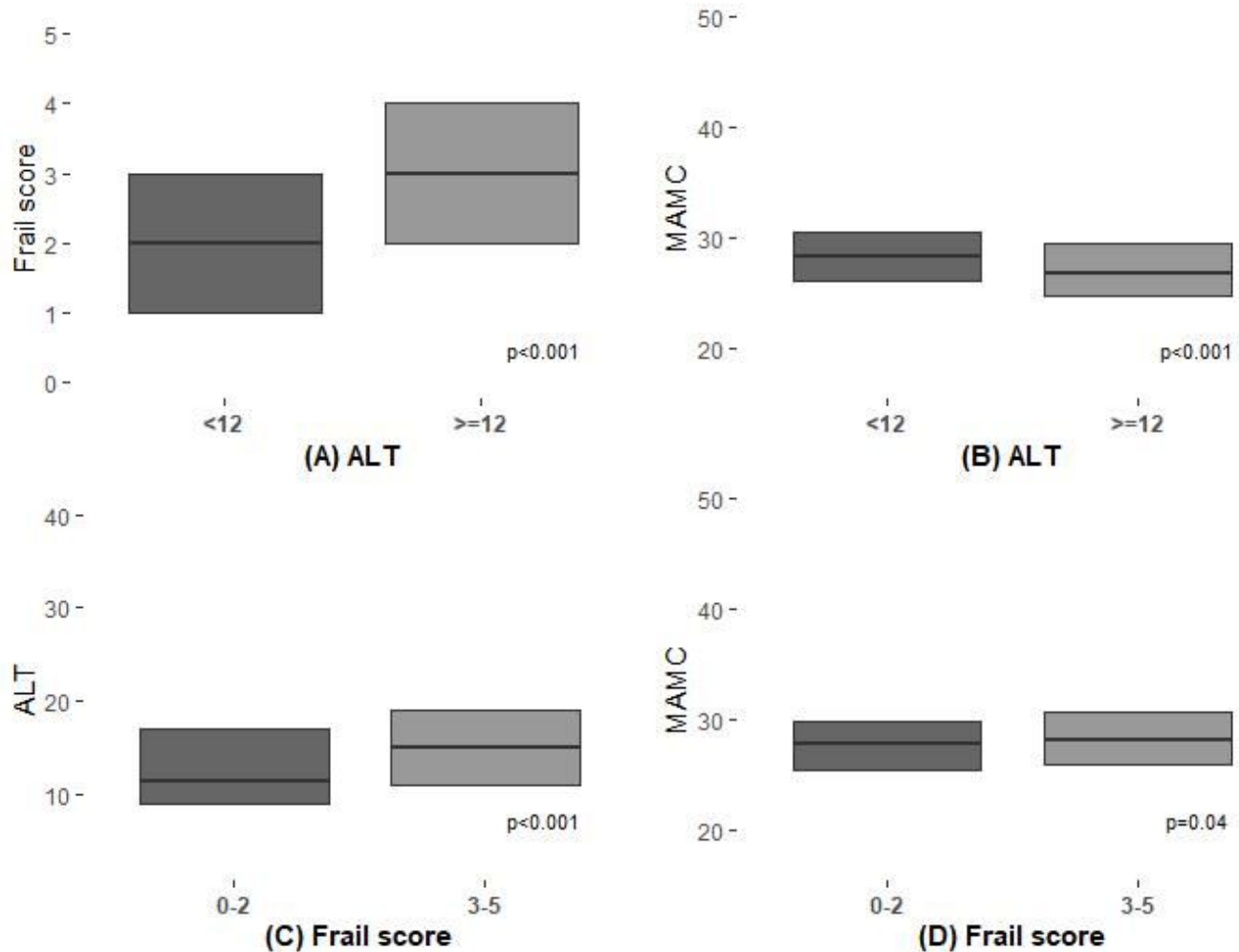

$$
50-
$$$$
\text { (B) ALT }
$$$$
\sum_{30-}^{40-}
$$$$
20-
$$
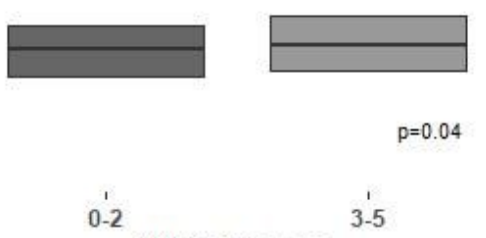

(D) Frail score

Figure 2 


\section{0 day readmission by serum ALT}

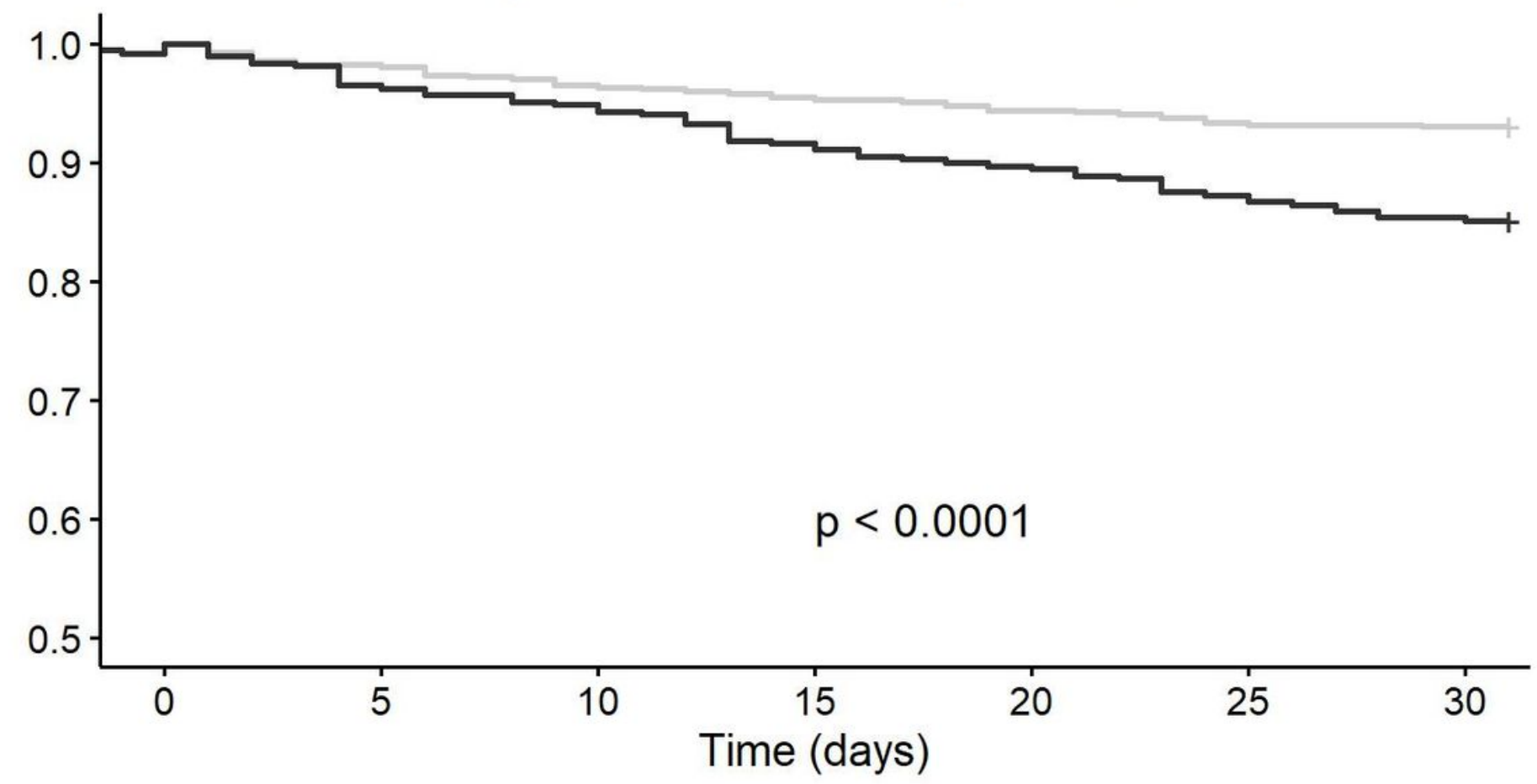

Number at risk

$\begin{array}{rrrrrrrr}<12 & 573 & 563 & 553 & 547 & 541 & 535 & 533 \\ >=12 & 366 & 356 & 350 & 338 & 331 & 322 & 315\end{array}$

Figure 3

30-days readmission according to serum ALT activity. 


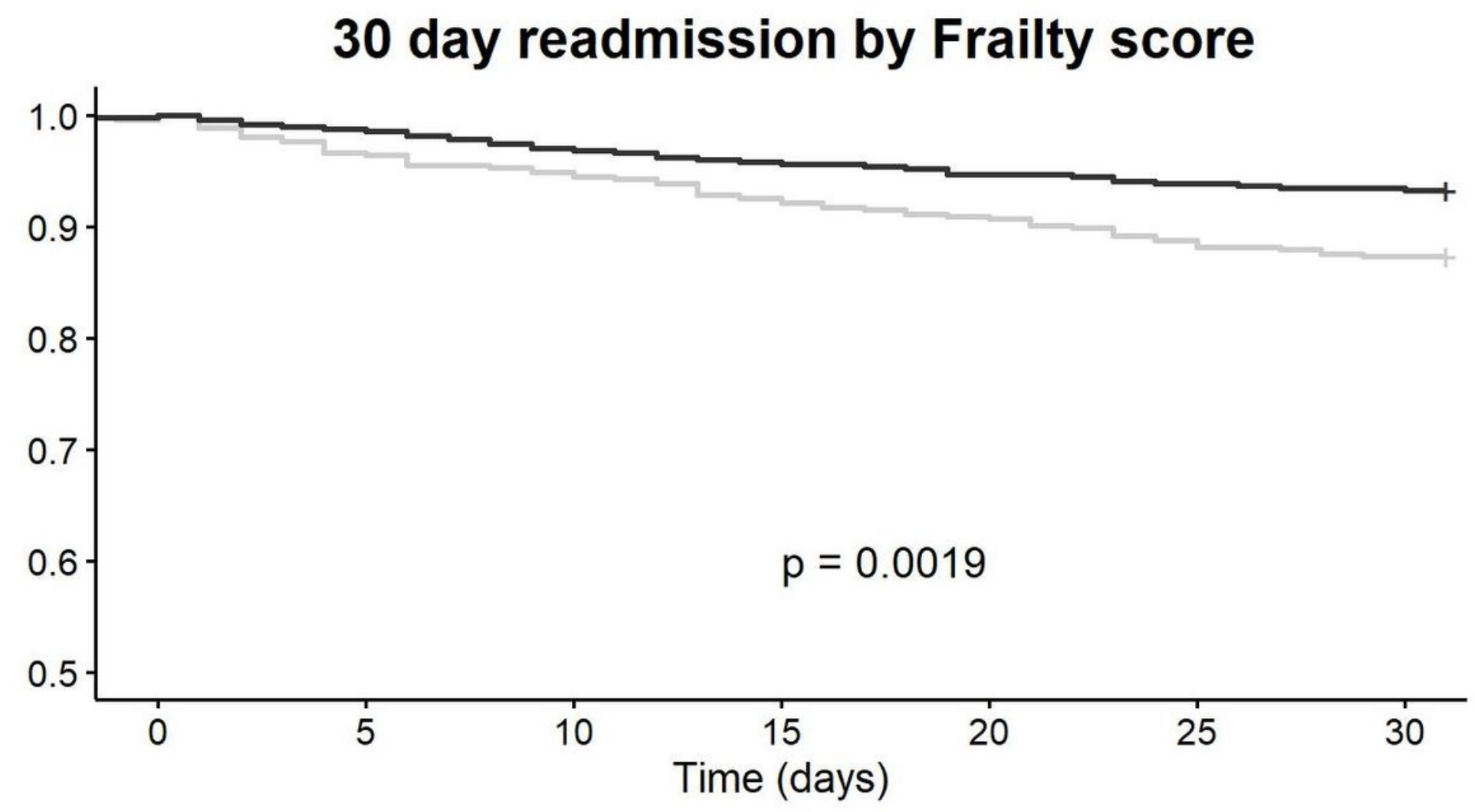

Number at risk

$\begin{array}{rrrrrrrr}0-2 & 504 & 489 & 480 & 468 & 460 & 449 & 442 \\ 3-5 & 473 & 468 & 460 & 454 & 449 & 445 & 443\end{array}$

Figure 4

30-days readmission according to FRAIL questionnaire classes. 